\title{
ARE ADIPOCYTES AND ROS VILLAINS, OR ARE THEY PROTAGONISTS IN THE DRAMA OF LIFE? THE MURBURN PERSPECTIVE
}

\author{
Vivian David Jacob and Kelath Murali Manoj* \\ Satyamjayatu: The Science \& Ethics Foundation, Kulappully, Shoranur-2 (PO), Palakkad District, Kerala, India
}

\begin{abstract}
Several questions remain unanswered regarding the roles and interactive dynamics of reactive oxygen species (ROS) and lipids/adipocytes. ROS have been conventionally associated with deleterious effects in biological systems, especially correlated with metabolic disorders exemplified by diabetes, obesity, cancer, atherogenesis, etc. Adipocytes, originally perceived as mere lipid-storing cells, were also associated with such metabolic disorders. In later times, adipose tissue was shown to have several favorable metabolic and physiological functions. Similarly, ROS were also acknowledged with favorable roles in cellular signaling. Very recently, ROS have been shown to be indispensable protagonists of key life-sustaining routines such as oxidative phosphorylation, thermogenesis and xenobiotics' metabolism. In the light of these developments, herein, we attempt to address why different research groups derive data that project/infer contrasting correlations of ROS and lipids with good health. We advocate that rather than seeing ROS and fat deposition as deleterious to health, the modality of their generation, loci of presence and the relative amounts/distribution in milieu are the crucial factors that determine their interactions/roles (and thereby, the resulting physiology!) in miscellaneous microenvironments.
\end{abstract}

Adipobiology 2019; 10: 7-16

Keywords: lipids, adipocytes, murburn concept/scheme, reactive oxygen species (ROS), metabolic disorder

Received 29 November 2018, revised 14 December 2018, accepted 15 December 2018.

Correspondence: Dr Kelath Murali Manoj, Satyamjayatu: The Science \& Ethics Foundation, Kulappully, Shoranur-2 (P0),

Palakkad District, Kerala-679122, India. E-mail: satyamjayatu@yahoo.com

\section{Introduction}

For decades, ROS (reactive oxygen species) have been seen as toxic and wasteful byproducts of biological processes like oxidative phosphorylation and xenobiotic metabolism. The research for anti-oxidants (molecules that scavenged ROS) gained momentum due to the correlation of ROS in cancer progression, ageing, apoptosis and oxidative damage to genes and proteins (1-2). Similarly, fatty tissue and free-lipid deposition were seen to have primarily negative connotations towards maintenance of good health (3). In recent times, the perceptions in the pertinent field of ROS-lipid interactions have undergone significant changes and this write-up aims to capture the salient aspects of the interactive dynamics of ROS and lipids/ adipocytes.

\section{Various ROS and their well-studied roles \\ ROS (reactive oxygen species), consti- tutes a set of "atom-molecule-ion-rad- ical" entities derived from the normal triplet molecular dioxygen, which is the abundant species present in atmosphere. This common oxygen species, ${ }^{3} \mathrm{O}_{2}$, is}


thus represented because the presence of two unpaired electrons in the bonded structure gives a "triplet spin multiplicity" spectroscopic signature when a magnetic field is applied. Due to "spin rules", the triplet oxygen does not pose high reactivity with most biomolecules. Table 1 provides the details of oxygen and its derivatives that form the simplest classes of ROS. Besides the ones listed below, ozone $\left(\mathrm{O}_{3}\right.$, or trioxygen, a neutral triatomic molecule) and various other species incorporating nitrogen (e.g. nitric oxide, peroxynitrite), halogen (e.g. hypochlorous acid, chlorite, etc.), carbon (of the nature- $\mathrm{RO}^{*}, \mathrm{ROO}^{*}$, etc.) atoms, are also examples of more diverse types of ROS encountered in biological systems.

Of all the ROS species, the superoxide ion radical is the one most abundantly found in physiological $\mathrm{pH}$ and can also exist as hydroperoxyl radical which can, more easily, percolate through the phospholipid bilayer. Hydroxyl radical is a very highly reactive species that can damage nucleic acids, peptides and lipids severely. Hydrogen peroxide is relatively less reactive and formed mostly from the reaction of superoxide with the enzyme superoxide dismutase. Peroxide can cause damage to DNA by producing the hydroxyl radical. Singlet oxygen $\left({ }^{1} \mathrm{O}_{2}\right)$ is deemed to be extremely toxic and can cause DNA and tissue level damage. It is mostly produced during neutrophil activation. Ozone $\left(\mathrm{O}_{3}\right)$ is produced during inflammatory process in vivo and can be a strong oxidizing agent forming reaction intermediates with biological molecules that may lead to aberrations. Such pathophysiological interactions of ROS with biological molecules have been well documented in scientific literature (4-11). In the last couple of decades, the roles of ROS as molecular signals/ messengers have been reported, explored and some cases like NO have been well-established (12-17).

\section{Types of adipocytes and their perceived functions}

Adipocytes are cells that store excess energy (lipid reserves) in the form of triglycerides and tissues incorporating such cells also provide mechanical support and insulation to organisms. Recently, adipose tissue is also considered a major endocrine and paracrine organ of the human organism. A typical demarcation of adipose tissue based on its coloration divides it into 2 types: brown adipose tissue (BAT) and white adipose tissue

Table 1. Electronic distribution and naming conventions of select oxygen-centered species

\begin{tabular}{|l|l|l|l|l|l|l|l|l|l|}
\hline Oxygen species & Notation & \multicolumn{1}{|c|}{ Stature (charge) \& relevant pK (if any) } & \multicolumn{5}{|c|}{ Electronic orbitals } \\
\hline Triplet Oxygen & ${ }^{2} \mathrm{O}_{2}$ & Diatomic diradical molecule (0). (Normal dioxygen) & $\uparrow \downarrow$ & $\uparrow \downarrow$ & $\uparrow \downarrow$ & $\uparrow \downarrow$ & $\uparrow \downarrow$ & $\uparrow$ & $\uparrow$ \\
\hline Oxygen & $\mathrm{O}$ & Atom (0); transient and very reactive & $\uparrow \downarrow$ & $\uparrow \downarrow$ & $\uparrow \downarrow$ & & & \\
\hline Singlet Oxygen & $1_{2} \mathrm{O}_{2}$ & $\begin{array}{l}\text { Diatomic molecule (0) } \\
\text { (Excited dioxygen; more reactive to organics than } \\
\text { singlet oxygen) }\end{array}$ & $\uparrow \downarrow$ & $\uparrow \downarrow$ & $\uparrow \downarrow$ & $\uparrow \downarrow$ & $\uparrow \downarrow$ & $\uparrow \downarrow$ & \\
\hline Superoxide & $\mathrm{O}_{2}^{*}$ & $\begin{array}{l}\text { Diatomic radical ion (-); becomes triatomic } \\
\text { perhydroxyl/hydroperoxyl uncharged radical on } \\
\text { protonation at pH 4.8. (Protonated species more } \\
\text { reactive to organics than superoxide ion.) }\end{array}$ & $\uparrow$ & $\uparrow \downarrow$ & $\uparrow \downarrow$ & $\uparrow \downarrow$ & $\uparrow \downarrow$ & $\uparrow \downarrow$ & $\uparrow$ \\
\hline Peroxide & $\mathrm{H}_{2} \mathrm{O}_{2}$ & $\begin{array}{l}\text { Tetra-atomic molecule (0); somewhat reactive, } \\
\text { becomes triatomic hydroperoxide ion on } \\
\text { deprotonation at 11.7. }\end{array}$ & $\uparrow \downarrow$ & $\uparrow \downarrow$ & $\uparrow \downarrow$ & $\uparrow \downarrow$ & $\uparrow \downarrow$ & $\uparrow \downarrow$ & $\uparrow \downarrow$ \\
\hline Hydroxyl & $\mathrm{OH}^{*}$ & $\begin{array}{l}\text { Di(hetero)atomic uncharged radical (0), one of the } \\
\text { most reactive species known, 11.5. Deprotonated } \\
\text { species (O*-) less reactive. }\end{array}$ & $\uparrow \downarrow$ & $\uparrow \downarrow$ & $\uparrow \downarrow$ & $\uparrow$ & & \\
\hline Hydroxide & $\mathrm{OH}^{-}$ & $\begin{array}{l}\text { Di(hetero)atomic ion (-); not very reactive, becomes } \\
\text { triatomic water molecule on protonation. }\end{array}$ & $\uparrow \downarrow$ & $\uparrow \downarrow$ & $\uparrow \downarrow$ & $\uparrow \downarrow$ & & \\
\hline Oxide & $\mathrm{O}^{2-}$ & Monoatomic ion (--) & $\uparrow \downarrow$ & $\uparrow \downarrow$ & $\uparrow \downarrow$ & $\uparrow \downarrow$ & \\
\hline Water & $\mathrm{H}_{2} \mathrm{O}$ & Triatomic molecule (0), 14. & $\uparrow \downarrow$ & $\uparrow \downarrow$ & $\uparrow \downarrow$ & $\uparrow \downarrow$ & & \\
\hline
\end{tabular}


(WAT). The multilocular BAT contains lower levels of lipids and more number of mitochondria when compared to WAT (18). Brown adipose tissue was earlier perceived as specific to infants and rodents as a site for non-shivering thermogenesis but recent finds have revealed its presence in adult humans as well. The mechanism of thermogenesis in BAT was essentially understood to be owing to two phenomena: lipolysis and dissipation of transmembrane potential formed by proton pumps in mitochondrial membrane (19). Some WAT undergo browning and are called "inducible, beige, or brite" adipose tissue (20). Figure 1 shows the schematic differentiation of the three types of adipose cells/tissues. However, recent studies also show that adipose tissue is not homogenous and varies in their metabolic profiles by depot-specificity and location (21). At present, it is not exactly clear how the various genetic and hormonal controls achieve the switching of different types of adipose tissues.

\section{An update on the origin and relevance of ROS in biological systems}

Several external agents are known to act as sources that lead to generation of ROS, as shown in the top panel of Figure 2. The parsing of these agents is into three types - physical, chemical and foodstuff. External physical agents like various high-energy photons (of X-rays, cosmic rays, gamma rays, UV-light, etc.) and ionizing radiations (like alpha and beta rays) could impart sufficient energy for molecular breakage at various sites, leading to the generation of various radicals and ROS within (2223). Chemicals like natural alkaloids, xenobiotics like halogenated organics, heavy metals and their salts, etc. are known ROS generators. Besides, foodstuff as exemplified by processed meat, used oil, alcoholic beverages, etc. are also known to lead to ROS generation. The function of ROS within the organism has been viewed under two lights- primarily pathological implications (immune responses, phagocytosis, and several diseases/disorders) and secondarily for the purpose of molecular signaling (like nitric oxide, superoxide, etc.). The internal sites/organelles where ROS generation is known to be high are- mitochondria, endoplasmic or sarcoplasmic reticulum, and peroxisomes. This is the classical way of seeing ROS dynamics with respect to its interaction with various agents.

Our group's research works have dwelled on the utility of ROS as an electron transfer and group transfer agent in routine metabolism. We have shown that ROS and diffusible species are responsible for electron/moiety transfers seen in heme/ flavin enzymes mediated reactions (24-35), which explain the metabolism of xenobiotics in hepatocyte endoplasmic reticulum
BROWN ADIPOCYTE

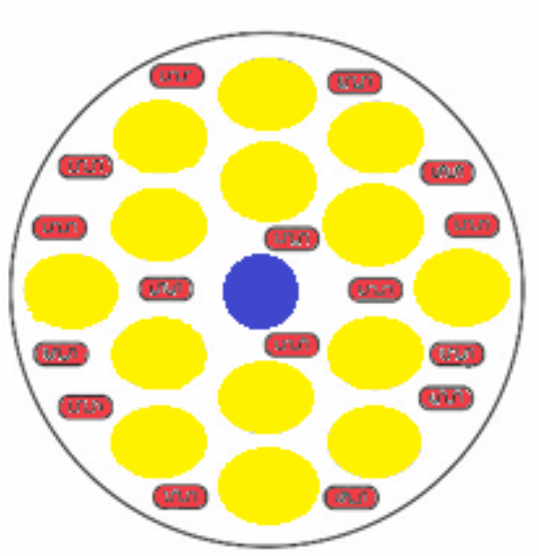

Densely packed small lipid droplets High density of mitochondria
BEIGE (BRITE) ADIPOCYTE

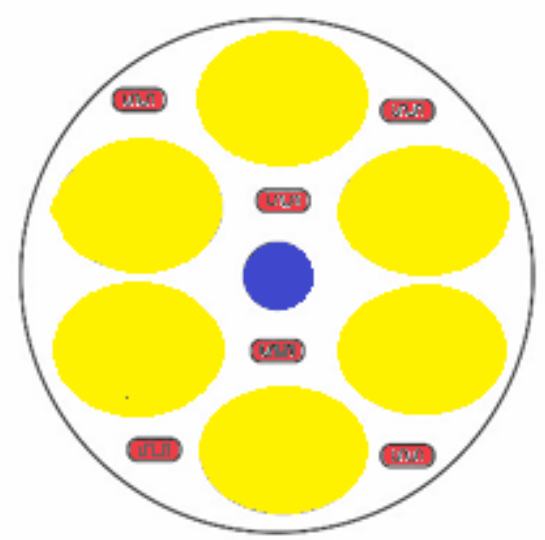

Moderately packed lipid droplets Moderate density of mitochondria
WHITE ADIPOCYTE

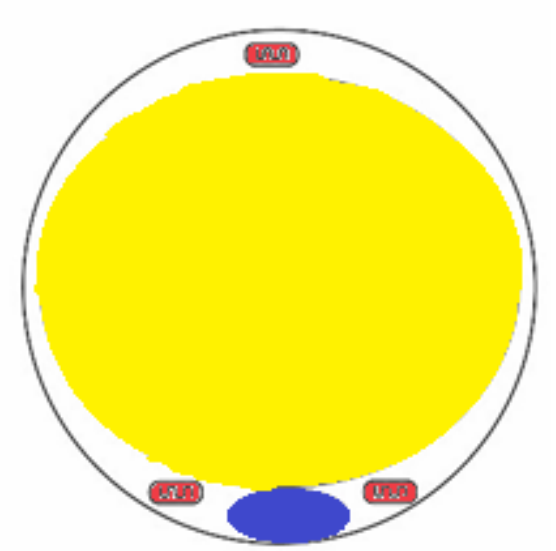

Large single lipid droplet Low density of mitochondria

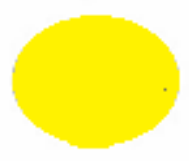

LIPID DROPLET
NUCLEUS

Figure 1. Schematic rendition of the different types of adipocytes 
(microsomes) (36-38), oxidative phosphorylation in mitochondria (39-41), thermogenesis mediated by uncoupling proteins in BAT (41-42), and maverick physiological dose responses (35, 43). This new metabolic/physiological paradigm that invokes reactions mediated via diffusible reactive species was recently called murburn concept $(34-41,43)$. Therefore, it is now definitive that production of ROS in cellular systems cannot be seen as a pathological or cellular signaling process alone. The generation and utilization of ROS should now be seen as an obligatory "catalytic outcome" that resulted due to evolutionary pressures. This is because cells evolved to capitalize on the fast reactions mediated by oxygen centered radicals and the high potentials of these radicals could activate even non-activated carbons, enabling facile metabolism. The predominantly hydrophobic organic molecules in the lipid cellular membranes would have high adsorption for the organic molecules. Retention of these mol- ecules would progressively destroy cell structure and function. So, the generation of ROS enabled the attack on these xenobiotics or alien molecules, thereby rendering them polar (as a hydroxyl group is introduced) and that would in turn be subjected to a "cleansing out" by water, the solvent of life. If ROS were to be bad, we cannot explain why millions of years of evolution could not bring about the structural mandates so that the "deleterious and chaotic" ROS were not produced by the proteins/organelles of prokaryotes and eukaryotes.

Therefore, a more holistic functional classification for ROS dynamics is presented within the bottom panel of Figure 2. The new perspective is captured by three "actions"- introduction, induction and production. ROS can be directly introduced into the living system (via smoke or tissue burning) or indirectly induced within the organism by an exposure to physical agents (like high-energy or ionizing radiations). Internal (in situ or in

\section{CONVENTIONAL VIEW}

\section{EXTERNAL SOURCES}

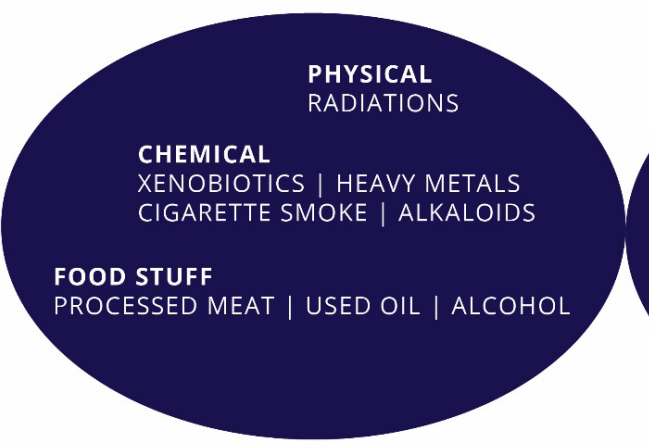

INTERNAL SOURCES

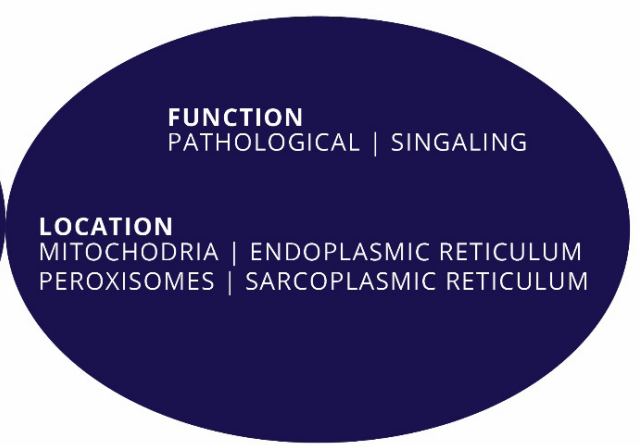
PEROXISOMES | SARCOPLASMIC RETICULUM

\section{UPDATED PERSPECTIVE}

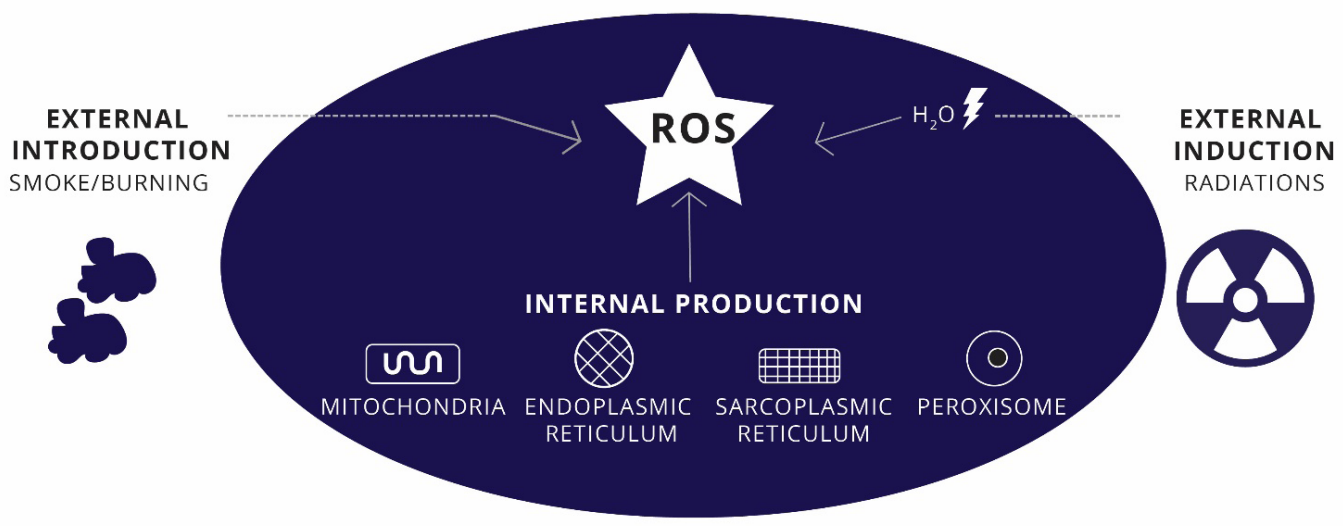

Figure 2. ROS dynamics within cells: conventional and updated perceptions 
vivo) metabolism of several molecules occurs with the obligatory production and utilization of ROS at mitochondria, endoplas$\mathrm{mic} /$ sarcoplasmic reticulum, peroxisomes, etc. Therefore, ROS production within cells is no more to be seen as a pathological attribute (wasteful or toxic side-product). However, this is not to say that ROS is always beneficial. This metabolic facet is both physiological and at times, could end up being pathological. Just like any radical with high reaction potential, ROS is also capable of grave damage to living systems. The paradigm change of ROS from being a villain (pathological effects), to the side-kick (cellular messenger) and finally to a benevolent cum indispensable protagonist (catalytic agent) is evident with the analysis of scientific literature through the past decades (13, 40-41, 43-46).

\section{The perception of functional roles played by free-lipids and lipid-laden cells/tissues}

Just like the change in perceptions on ROS, the case of adipose tissue has also undergone a radical change over the decades. Adipose tissue was also seen under negative light with increasing incidence of obesity and associated metabolic pathology (18, 47). However, recently, adipocytes have been acknowledged for their role in nutrient homeostasis, energy balance and release of adipokines, endocrine signaling molecules and protein factors $(18,48-50)$. Also, it is known that Eskimos eat animal blubber in huge amounts, and they still have a long, active and healthy life. While low density lipoproteins are deemed bad, high density lipoproteins are good. Therefore, lipids and their storage depots (adipocytes), per se, cannot be bad for health. Lipids (and not protein-capsids or glycan-walls!) evolved as the fundamental biological membrane choice because of its inherent fluidity and electron-rich nature that could form organized structures and embed proteins. The obligatory requirement and favorable roles of lipids in life is endorsed by the finding that animals even evolved to have a separate sense of taste for "fats" (51).

Therefore, the consensus is emerging that nutrient intake, genetic make-up and idiosyncratic metabolic disposition is needed to make a call on the "goodness" or "badness" of free-lipids and lipid-laden cells in a case-wise manner. More evaluation on how various cells, biomolecules and reactive species interact/react with adipocytes is necessary for us to understand the latter's role in pathology and physiological cascades. This could perhaps enable an adipose-tissue directed pharmacotherapy also (52).

\section{Addressing the problematic ROS-lipid (adipocyte) interaction dynamics}

There is a plethora of data supporting the malevolent role of ROS in several diseases. However, several other research groups have published data which support beneficial roles of ROS in those same diseases.

From the broad perceptions that ROS causes deterioration of lipids and lipid membranes, we now have specific information on how ROS react with lipid targets. These reactions most often lead to lipid peroxidations (9) which generates products like RCCs (reactive carbonyl compounds), alkanes and ketones. In turn, these products form cross-links and adducts with cellular constituents to form end products referred to as advanced lipid peroxidation end products (ALEs) (8). The RCCs can be further classified under three major groups (53):

1. the $\alpha, \beta$-unsaturated aldehydes like 4-hydroxy-2-nonenal (4-HNE) and acrolein

2. di-aldehydes like malondialdehyde and glyoxal

3. cheto-aldehyde (methylglyoxal) and isoketals (levuglandins)

Some of these molecular species (as exemplified in 1 \& 2 above) are implicated in artherosclerosis, chronic renal failure (54-58), neurodegenerative diseases like Alzheimers, Parkinsons, etc., (59-60), carcinogenesis (61-63) and chronic inflammatory diseases $(64,65,66)$. All these diseases could potentially involve adverse ROS-lipid interactions. While species such as 4-HNE are implicated in disease and cell death, it should also be noted that evidence is also available where 4-HNE promotes cell survival and signaling in gene expression, antioxidant capacity, adaptive response and effect anti-cancer properties (6771). It was argued therein that the outcomes depend on cellular metabolic circumstances and cell type, etc (72). Therefore, it can be seen that the interaction of ROS with adipocytes (and lipids therein) can also lead to positive effects.

Similarly, in some research studies, ROS are assigned a villainous role in the development of atherosclerosis or plaque formation in arteries (a condensed deposition of free lipids, calcium and miscellaneous substances that blocks the free flow of blood) (73-74). Nevertheless, in another study, Nox4, a ROS generating enzyme is implicated in anti-atherosclerotic function (75).

The same is the case for adipocytes. Some research groups provide evidence where adipocytes induce oxidative stress through release of ROS and ROS-inducing factors (76-79) and other groups give evidence of beneficial role of adipocytes in nutrient homeostasis, energy balance and release of endocrine signaling molecules and protein factors $(18,49,50)$.

Though the distribution and dynamics of ROS have been studied in lipid bilayers (80), the real-time detection and quantification of various ROS (and their metabolic intermediates) is a major experimental challenge, as these species have highly dynamic and interactive equilibriums with their surrounding entities. Various labs use different probes with different settings. So, this could also lead to a major reason of disagreement be- 
tween various research groups, and this predicament stands to pose significant problems in the times to come. Moving on, if we look at the conflicting research data presented, it is evident that ROS is benevolent when present in mild to moderate levels in specific loci and malevolent when present in high concentrations or in undesired loci. In this light, murburn concept, a new mechanistic paradigm, addresses the catalysis mediated by in situ generated ROS and diffusible reactive species (34-41, 43). This stochastic paradigm can give both selective/ordered reactions, and can also be subjected to fair amounts of uncertainties/ chaos by the presence of trace amounts of additives. Therefore, the amphipathic lipids and their derivatives can give concentration-dependent and contrasting outcomes between systems and experimental setups. We have demonstrated some of the complex effects, underpinning mechanistic principles and constitutive controls $(32,35-36,43)$. In the murburn perspective, besides the classical affinity-based interactions, other facets like dynamic partitioning, relative concentrations, reaction microenvironments' dielectrics, availability of protons, spin state of reacting species, etc. are slated to be key governing constitutive principles that determine reaction outcomes (kinetics, stoichiometry, etc.). While it is clear how high amount of ROS can lead to deleterious effects, the tissue/loci-specific role change of ROS needs special attention, in the light of the contrasting findings and the possible explanations that murburn concept can afford. It has been proposed that timing, source and tissue specific effects of ROS would be beneficial in understanding the discrepancy of evidence presented in basic research and clinical studies (81). The tissue that is most evidently associated with ROS production and interaction is adipose tissue. Hence it is most important to keep murburn concept in perspective and examine the action of ROS within and outside adipose tissue to understand how ROS can have both deleterious and beneficial effects with respect to its location.

There is also emerging evidence that cellular liquid phases have membrane-less aggregates that compartmentalize molecules based on their chemical and physical properties. These structural aggregations also serve several functional attributes of the cell (82-85). We project that ROS-lipid interactive dynamics could affect such aggregations, thereby affecting normal or pathological physiology. For now, it is evident that the earlier viewpoints need to be revamped to accommodate the diverse set of experimental observations available. Clearly, not just in peroxisomes and phagocytes, ROS has an obligatory physiological role in mitochondria and the membranous cytoplasmic/ sarcoplasmic reticulum. Therefore, ROS can no more be seen as a wasteful or toxic byproduct. Figure 3 captures the essential shift in perspective in this regard. As seen, lipids and lipidladen tissues serve the function of retaining integrity, affording a platform for ROS reactions, and enable conservation of heat
CONVENTIONAL PERCEPTION

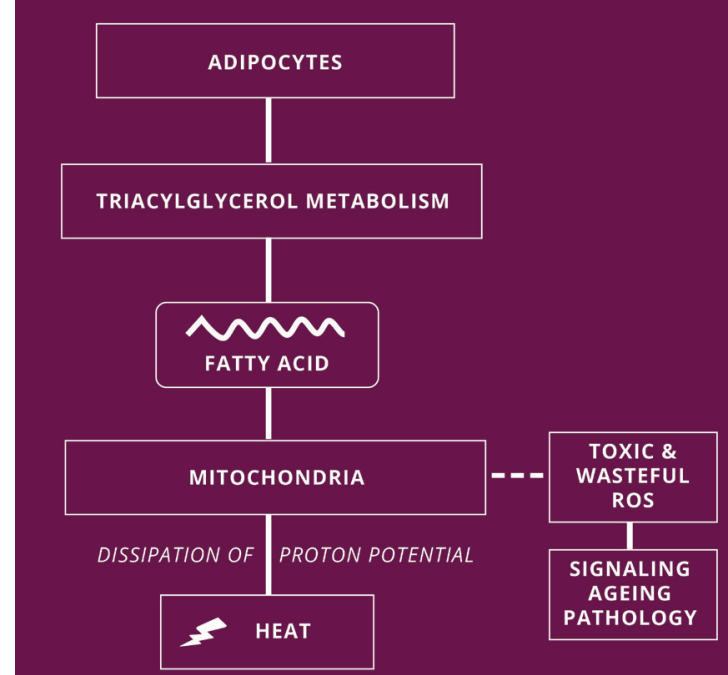

MURBURN PERSPECTIVE

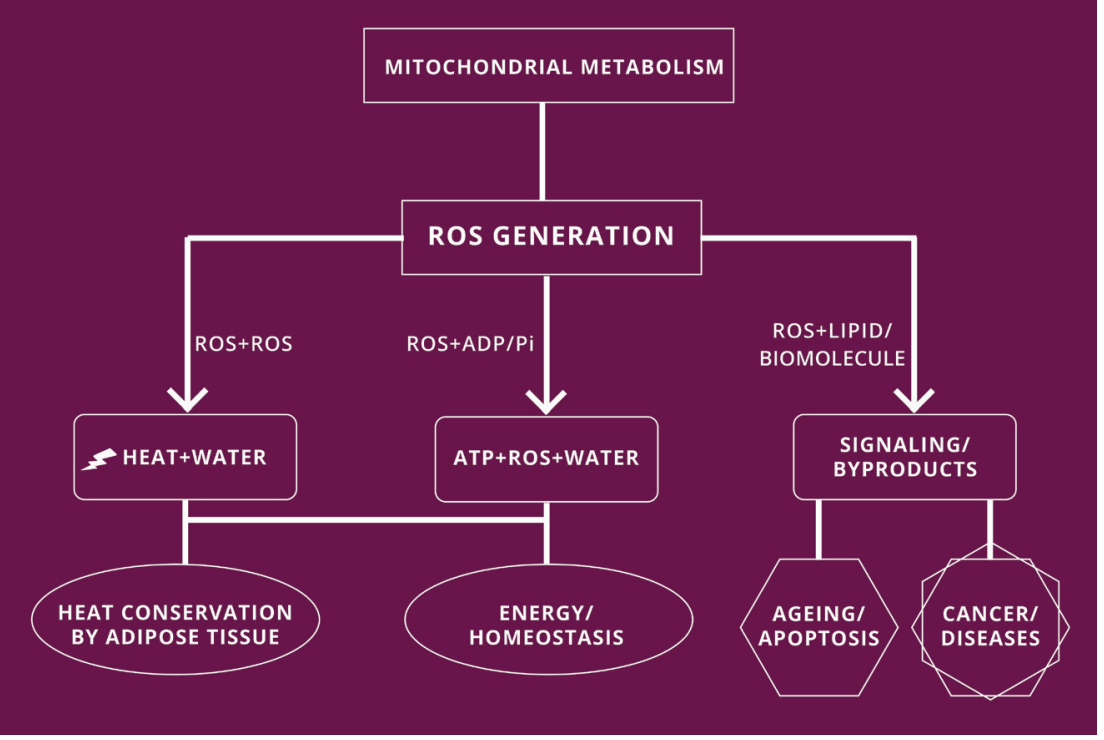

Figure 3. The interaction paradigms of ROS and lipids/adipocytes 
by virtue of low heat capacity of oils (in comparison to water). It must be remembered that heat energy is one of the unsung heroes of metabolism- kinetics depend crucially on temperature! With these fundamental outlooks, reoriented research agenda can generate better understanding.

\section{Conclusion}

To recapitulate- it is true that DROS are implicated in oxidative stress, several diseases and pathophysiological states. It is also true that enzymes like catalase, peroxidase, SOD, etc. deplete DROS and some antioxidants alleviate harmful effects of DROS. However, in physiology, any entity has its utility with respect to the context of location, time and quantity. Our works have clearly shown that the aqueous phase redox enzymes (cited above) cannot compete for the small amounts of DROS dynamically generated at the phospholipid interface. Further, the thermodynamic, kinetic and reaction chemistry logic strongly endorse the utility of DROS in several metabolic and physiological processes. Just because a cut-injury in the kitchen most probably results from knife-abuse, one does not infer that knives do not have any positive role in the kitchen! Also, one may find gloves and cutting-boards to hold and handle knives in the kitchen. Their presence too does not imply that knives have no constructive culinary roles! (In this analogy- knives, gloves and cutting boards are equivalent to DROS, redox enzymes and antioxidants respectively.)

In the light of a plethora of emerging experimental evidences and theoretical insights, we should also acknowledge DROS' roles as catalysts and protagonists in cellular metabolism, homeostasis, energetics, and signaling.

\section{Acknowledgements}

The work was powered by Satyamjayatu: The Science \& Ethics Foundation. KMM dedicates this manuscript to the fond memories of Lowell P. Hager (Late, Professor Emeritus at UIUC, Member of NAS, USA).

\section{Conflict of interests}

There are no conflicts of interests to disclose in the context.

\section{Author contributions}

Both VDJ and KMM wrote the paper. KMM conceived the ideas and VDJ made the figures.

\section{References}

1. Valko M, Leibfritz D, Moncol J, Cronin MTD, Mazur M, Telser J. Free radicals and antioxidants in normal physiological functions and human disease. Int J Biochem Cell
Biol 2007; 39: 44-84. doi:10.1016/j.biocel.2006.07.001.

2. Willcox JK, Ash SL, Catignani GL. Antioxidants and prevention of chronic disease. Rev Crit Rev Food Sci Nutr 2004; 44: 275-295. doi: 10.1080/10408690490468489.

3. Parthasarathy S, N Santanam, S Ramachandran, O Meilhac. Oxidants and antioxidants in atherogenesis: an appraisal. $J$ Lipid Res 1999; 40: 2143-2157. doi:10.1002/jcc.20084.

4. Halliwell B, Gutteridge JMC. Free Radicals in Biology and Medicine. Clarendon Press, 2007. DOI: 10.1002/jcc.20084.

5. Droge W. Free radicals in the physiological control of cell function. Physiol Rev 2002; 82: 47-95. DOI: 10.1152/physrev.00018.2001.

6. Dizdaroglu $M$, Jaruga $\mathrm{P}$, Birincioglu $M$, Rodriguez $H$. Free radical-induced damage to DNA: mechanisms and measurement. Free Radic Biol Med 2002; 32: 1102-1115. doi:10.1016/S0891-5849(02)00826-2

7. Hofer T, Badouard C, Bajak E, Ravanat JL, Mattsson A, Cotgreave IA. Hydrogen peroxide causes greater oxidation in cellular RNA than in DNA. Biol Chem 2005; 386: 333337. doi: 10.1515/BC.2005.040.

8. Negre-Salvayre A, Coatrieux C, Ingueneau C, Salvayre R. Advanced lipid peroxidation end products in oxidative damage to proteins. Potential role in diseases and therapeutic prospects for the inhibitors. Br J Pharmacol 2008; 153: 6-20. doi:10.1038/sj.bjp.0707395.

9. Yin $\mathrm{H}, \mathrm{Xu}$ L, Porter NA. Free Radical Lipid Peroxidation: Mechanisms and Analysis. Chem Rev 2011; 111: 59445972. doi:10.1021/cr200084z.

10. Dean RT, Fu S, Stocker R, Davies MJ. Biochemistry and pathology of radical-mediated protein oxidation. Biochem $J$ 1997; 324: 1-18. doi:10.1042/bj3240001.

11. Butterfield DA, Koppal T, Howard B, et al. Structural and functional changes in proteins induced by free radical-mediated oxidative stress and protective action of the antioxidants N-tert-butyl-alpha-phenylnitrone and vitamin E. Ann NY Acad Sci 1998; 854: 448-462. doi:10.1111/j.1749-6632.1998.tb09924.x.

12. Ignarro LJ, Buga GM, Wood KS, Byrns RE, Chaudhuri G. Endothelium-derived relaxing factor produced and released from artery and vein is nitric oxide. Proc Natl Acad Sci U S A 1987; 84: 9265-9269. doi:10.1073/ pnas.84.24.9265.

13. D’Autréaux B, Toledano MB. ROS as signalling molecules: mechanisms that generate specificity in ROS homeostasis. Nat Rev Mol Cell Biol 2007; 8: 813. DOI: 10.1038/nrm2256.

14. Wu W.S. The signalling mechanism of ROS in tumor progression. Cancer Metastasis Rev 2006; 25: 695-705. doi: 10.1007/s10555-006-9037-8. 
15. Zhang J, Wang X, Vikash V, et al. ROS and ROS-Mediated Cellular Signaling. Oxid Med Cell Longev 2016; 2016: 4350965. doi:10.1155/2016/4350965.

16. Schieber M, Chandel NS. ROS function in redox signaling and oxidative stress. Curr Biol 2014; 24: R453-62. DOI: 10.1016/j.cub.2014.03.034.

17. Howlett R. Nobel award stirs up debate on nitric oxide breakthrough. Nature. 1998; 395: 625. https://doi. org/10.1038/27019.

18. Rosen ED, Spiegelman BM. Adipocytes as regulators of energy balance and glucose homeostasis. Nature 2006; 444: 847-853. doi:10.1038/nature05483.

19. Cannon B, Nedergaard J. Brown adipose tissue: function and physiological significance. Physiol Rev 2004; 84: 277 359. doi:10.1152/physrev.00015.2003.

20. Giralt M, Villarroya F. White, brown, beige/brite: different adipose cells for different functions? Endocrinology 2013; 154: 2992-3000. doi:10.1210/en.2013-1403.

21. Casteilla L, Penicaud L, Cousin B, Calise D. Choosing an adipose tissue depot for sampling: factors in selection and depot specificity. Methods Mol Biol 2008; 456: 23-38. doi:10.1007/978-1-59745-245-8_2.

22. Kawamura K, Qi F, Kobayashi J. Potential relationship between the biological effects of low-dose irradiation and mitochondrial ROS production. J Radiat Res 2018; 59: ii91ii97. http://dx.doi.org/10.1093/jrr/rrx091.

23. Yamamori $\mathrm{T}$, Yasui $\mathrm{H}$, Yamazumi $\mathrm{M}$, et al. Ionizing radiation induces mitochondrial reactive oxygen species production accompanied by upregulation of mitochondrial electron transport chain function and mitochondrial content under control of the cell cycle checkpoint. Free Radic Biol Med. 2012; 53: 260-270. doi:10.1016/j.freeradbiomed.2012.04.033.

24. Manoj KM. Chlorinations catalyzed by chloroperoxidase occur via diffusible intermediate(s) and the reaction components play multiple roles in the overall process. Biochim Biophys Acta 2006; 1764: 1325-1339. doi:10.1016/j.bbapap.2006.05.012.

25. Manoj KM, Hager LP. Chloroperoxidase, a janus enzyme. Biochemistry 2008; 47: 2997-3003. doi:10.1021/ bi7022656.

26. Manoj KM, Baburaj A, Ephraim B, et al. Explaining the atypical reaction profiles of heme enzymes with a novel mechanistic hypothesis and kinetic treatment. PLoS One 2010; 5: e10601. doi:10.1371/journal.pone.0010601.

27. Manoj KM, Gade SK, Mathew L. Cytochrome P450 reductase: a harbinger of diffusible reduced oxygen species. PLoS One 2010; 5: e13272. doi:10.1371/journal.pone.0013272.
28. Andrew D, Hager L, Manoj KM. The intriguing enhancement of chloroperoxidase mediated one-electron oxidations by azide, a known active-site ligand. Biochem Biophys Res Commun 2011; 415: 646-649. doi:10.1016/j. bbrc.2011.10.128.

29. Gade SK, Bhattacharya S, Manoj KM. Redox active molecules cytochrome $\mathrm{c}$ and vitamin $\mathrm{C}$ enhance heme-enzyme peroxidations by serving as non-specific agents for redox relay. Biochem Biophys Res Commun 2012; 419: 211-214. doi:10.1016/j.bbrc.2012.01.149.

30. Parashar A, Manoj KM. Traces of certain drug molecules can enhance heme-enzyme catalytic outcomes. Biochem Biophys Res Commun 2012; 417: 1041-1045. doi:10.1016/j. bbrc.2011.12.090.

31. Gideon DA, Kumari R, Lynn AM, Manoj KM. What is the functional role of $\mathrm{N}$-terminal transmembrane helices in the metabolism mediated by liver microsomal cytochrome P450 and its reductase? Cell Biochem Biophys 2012; 63: 3545. doi:10.1007/s12013-012-9339-0.

32. Parashar A, Gade SK, Potnuru M, Madhavan N, Manoj KM. The curious case of benzbromarone: insight into super-inhibition of cytochrome P450. PLoS One 2014; 9: e89967. doi:10.1371/journal.pone.0089967.

33. Parashar A, Venkatachalam A, Gideon DA, Manoj KM. Cyanide does more to inhibit heme enzymes, than merely serving as an active-site ligand. Biochem Biophys Res Commun 2014; 455: 190-193. doi:10.1016/j.bbrc.2014.10.137.

34. Manoj KM, Gade SK, Venkatachalam A, Gideon DA. Electron transfer amongst flavo- and hemo-proteins: diffusible species effect the relay processes, not protein-protein binding. RSC Adv 2016; 6: 24121-24129. doi:10.1039/ C5RA26122H.

35. Manoj KM, Parashar A, Venkatachalam A, et al. Atypical profiles and modulations of heme-enzymes catalyzed outcomes by low amounts of diverse additives suggest diffusible radicals' obligatory involvement in such redox reactions. Biochimie 2016; 125: 91-111. doi:10.1016/j.biochi.2016.03.003.

36. Manoj KM, Parashar A, Gade SK, Venkatachalam A. Functioning of microsomal cytochrome P450s: Murburn concept explains the metabolism of xenobiotics in hepatocytes. Front Pharmacol 2016; 7: 161. doi:10.3389/ fphar.2016.00161.

37. Manoj KM, Venkatachalam A, Parashar A. Metabolism of xenobiotics by cytochrome P450: novel insights into the thermodynamics, kinetics and roles of redox proteins and diffusible reactive species. Drug Metab Rev 2016; 48: 41-42. doi:10.1080/03602532.2016.1191848. 
38. Venkatachalam A, Parashar A, Manoj KM. Functioning of drug-metabolizing microsomal cytochrome P450s: In silico probing of proteins suggests that the distal heme "active site" pocket plays a relatively "passive role" in some enzyme-substrate interactions. In silico Pharmacol 2016; 4: 2. doi:10.1186/s40203-016-0016-7.

39. Manoj KM. Debunking chemiosmosis and proposing murburn concept as the explanation for cellular respiration. Biomed Rev 2017; 28: 35-52. doi:10.14748/bmr.v28.4450.

40. Manoj KM. Aerobic respiration: Criticism of the proton-centric explanation involving rotary ATP synthesis, chemiosmosis principle, proton pumps and electron transport chain. Biochem Insi 2018. doi: 10.1177/1178626418818442.

41. Manoj KM, Parashar A, Jacob VD, Ramasamy S. Aerobic respiration: Proof of concept for the murburn perspective. 2018. doi: 10.1080/07391102.2018.1552896.

42. Manoj KM. Murburn scheme for thermogenesis mediated by uncoupling protein. 2018. arXiv:1812.06089 [q-bio.SC]

43. Parashar A, Gideon DA, Manoj KM. Murburn Concept: A molecular explanation for hormetic and idiosyncratic dose responses. Dose Response 2018; 16: 1559325818774421. doi:10.1177/1559325818774421.

44. Watson JD. Type 2 diabetes as a redox disease. Lancet 2014; 383: 841-843. doi:10.1016/S0140-6736(13)62365-X.

45. Mittler R. ROS Are Good. Trends Plant Sci 2017; 22: 11-19. doi:10.1016/j.tplants.2016.08.002.

46. Huo Y, Qiu W-Y, Pan Q, Yao Y-F, Xing K, Lou MF. Reactive oxygen species (ROS) are essential mediators in epidermal growth factor (EGF)-stimulated corneal epithelial cell proliferation, adhesion, migration, and wound healing. Exp Eye Res 2009; 89: 876-886. doi:10.1016/j. exer.2009.07.012.

47. Bray GA, Bellanger T. Epidemiology, trends, and morbidities of obesity and the metabolic syndrome. Endocrine 2006; 29: 109-117. doi:10.1385/ENDO:29:1:109.

48. Chaldakov GN, Stankulov IS, Aloe L. Subepicardial adipose tissue in human coronary atherosclerosis: another neglected phenomenon. Atherosclerosis 2001; 154: 237-238. doi:10.1016/S0021-9150(00)00676-6.

49. Trayhurn P. Endocrine and signalling role of adipose tissue: new perspectives on fat. Acta Physiol Scand 2005; 184: 285293. doi:10.1111/j.1365-201X.2005.01468.x.

50. Sethi JK, Vidal-Puig AJ. Thematic review series: adipocyte biology. Adipose tissue function and plasticity orchestrate nutritional adaptation. J Lipid Res 2007; 48: 1253-1262. doi:10.1194/jlr.R700005-JLR200.

51. Besnard P, Passilly-Degrace P, Khan NA. Taste of fat: A sixth taste modality? Physiol Rev 2016; 96: 151-176. doi:10.1152/ physrev.00002.2015.

52. Chaldakov GN, Fiore M, Tonchev AB, Aloe L. Adipopharmacology, a novel drug discovery approach: A metabotrophic perspective. Lett Drug Des Discov 2006; 3: 503-505. doi:http://dx.doi.org/10.2174/157018006778194835.

53. Vistoli G, De Maddis D, Cipak A, Zarkovic N, Carini M, Aldini G. Advanced glycoxidation and lipoxidation end products (AGEs and ALEs): an overview of their mechanisms of formation. Free Radic Res. 2013; 47: 3-27. doi:10.3 109/10715762.2013.815348.

54. Steinberg D. Low density lipoprotein oxidation and its pathobiological significance. J Biol Chem 1997; 272: 2096320966. 10.1016/S0006-3495(93)81518-2.

55. Palinski W, Rosenfeld ME, Yla-Herttuala S, Gurtner GC, Socher SS, Butler SW, et al. Low density lipoprotein undergoes oxidative modification in vivo. Proc Natl Acad Sci USA 1989; 86: 1372-1376. doi:10.1073/pnas.86.4.1372.

56. Fredrikson GN, Berglund G, Alm R, Nilsson JA, Shah PK, Nilsson J. Identification of autoantibodies in human plasma recognizing an apoB-100 LDL receptor binding site peptide. J Lipid Res 2006; 47: 2049-2054. doi: 10.1194/jlr. M600217-JLR200.

57. Siems W, Quast S, Carluccio F, Wiswedel I, Hirsch D, Augustin $\mathrm{W}$, et al. Oxidative stress in chronic renal failure as a cardiovascular risk factor. Clin Nephrol 2002; 58: S12S19.

58. Carluccio F, Siems W, Stefanelli G, Sommerburg O, Grune $\mathrm{T}$, Riedel $\mathrm{E}$, et al. Homocysteine in chronic renal failure in relation to renal anemia and to oxidative stress parameters 4-hydroxynonenal and malondialdehyde. Clin Nephrol 2002; 58: S26-S30.

59. Yoritaka A, Hattori N, Uchida K, Tanaka M, Stadtman ER, Mizuno Y. Immunohistochemical detection of 4-hydroxynonenal protein adducts in Parkinson disease. Proc Natl Acad Sci USA 1996; 93: 2696-2701.

60. Jenner P. Oxidative stress in Parkinson's disease. Ann Neurol 2003; 53:S26-36; S36-38. doi:10.1002/ana.10483.

61. Pierre F, Peiro G, Tache S, Cross AJ, Bingham SA, Gasc $\mathrm{N}$, et al. New marker of colon cancer risk associated with heme intake: 1,4-dihydroxynonane mercapturic acid. Cancer Epidemiol Biomarkers Prev 2006; 15: 2274-2279. doi: 10.1158/1055-9965.EPI-06-0085.

62. Pierre F, Tache S, Gueraud F, Rerole AL, Jourdan ML, Petit C. Apc mutation induces resistance of colonic cells to lipoperoxide-triggered apoptosis induced by faecal water from haem-fed rats. Carcinogenesis 2007; 28: 321-327. doi: 10.1093/carcin/bgl127. 
63. Weber LW, Boll M, Stampfl A. Hepatotoxicity and mechanism of action of haloalkanes: carbon tetrachloride as a toxicological model. Crit Rev Toxicol 2003; 33: 105-136. doi: 10.1080/713611034.

64. Grune T, Michel P, Sitte N, Eggert W, Albrecht-Nebe H, Esterbauer $\mathrm{H}$, et al. Increased levels of 4-hydroxynonenal modified proteins in plasma of children with autoimmune diseases. Free Radic Biol Med 1997; 23: 357-360. doi:10.1016/S0891-5849(96)00586-2.

65. Boldogh I, Bacsi A, Choudhury BK, Dharajiya N, Alam R, Hazra TK, et al. ROS generated by pollen NADPH oxidase provide a signal that augments antigen-induced allergic airway inflammation. J Clin Invest 2005; 115: 2169-2179. doi: 10.1172/JCI24422.

66. Almolki A, Taille C, Martin GF, Jose PJ, Zedda C, Conti $\mathrm{M}$, et al. Heme oxygenase attenuates allergen-induced airway inflammation and hyperreactivity in guinea pigs. Am J Physiol Lung Cell Mol Physiol 2004; 287: L26-L34. doi: 10.1152/ajplung.00237.2003.

67. Skorokhod OA, Caione L, Marrocco T, et al. Inhibition of erythropoiesis in malaria anemia: role of hemozoin and hemozoin-generated 4-hydroxynonenal. Blood 2010; 116: 4328-4337. doi:10.1182/blood-2010-03-272781.

68. Albright CD, Klem E, Shah AA, Gallagher P. Breast cancer cell-targeted oxidative stress: enhancement of cancer cell uptake of conjugated linoleic acid, activation of p53, and inhibition of proliferation. Exp Mol Pathol 2005; 79: 118125. doi:10.1016/j.yexmp.2005.05.005.

69. Sunjic SB, Cipak A, Rabuzin F, Wildburger R, Zarkovic N. The influence of 4-hydroxy-2-nonenal on proliferation, differentiation and apoptosis of human osteosarcoma cells. Biofactors 2005; 24: 141-148. doi:10.1002/biof.5520240117.

70. Cerbone A, Toaldo C, Laurora S, et al. 4-Hydroxynonenal and PPARgamma ligands affect proliferation, differentiation, and apoptosis in colon cancer cells. Free Radic Biol Med 2007; 42: 1661-1670. doi:10.1016/j.freeradbiomed.2007.02.009.

71. Pizzimenti S, Menegatti E, Berardi D, et al. 4-hydroxynonenal, a lipid peroxidation product of dietary polyunsaturated fatty acids, has anticarcinogenic properties in colon carcinoma cell lines through the inhibition of telomerase activity. J Nutr Biochem 2010; 21: 818-826. doi:10.1016/j. jnutbio.2009.06.005.

72. Ayala A, Munoz MF, Arguelles S. Lipid peroxidation: production, metabolism, and signaling mechanisms of malondialdehyde and 4-hydroxy-2-nonenal. Oxid Med Cell Longev 2014; 2014: 360438. doi:10.1155/2014/360438.
73. Cai H, Harrison DG. Endothelial dysfunction in cardiovascular diseases: the role of oxidant stress. Circ Res. 2000; 87: 840-844.

74. Bahorun T, Soobrattee MA, Luximon-Ramma V, Aruoma OI. Free radicals and antioxidants in cardiovascular health and disease. Internet J. Med. Update 2006; 1: 1-17. doi:10.4314/ijmu.v1i2.39839.

75. Schürmann C, Rezende F, Kruse C, et al. The NADPH oxidase Nox4 has anti-atherosclerotic functions. Eur Heart $J$ 2015; 36: 3447-56. doi: 10.1093/eurheartj/ehv460.

76. Le Lay S, Simard G, Martinez MC, Andriantsitohaina R. Oxidative stress and metabolic pathologies: from an adipocentric point of view. Oxid Med Cell Longev 2014; 2014: 908539. doi:10.1155/2014/908539.

77. Furukawa S, Fujita T, Shimabukuro M, et al. Increased oxidative stress in obesity and its impact on metabolic syndrome. J Clin Invest 2004; 114: 1752-1761. doi:10.1172/ JCI21625.

78. Curtis JM, Grimsrud PA, Wright WS, et al. Downregulation of adipose glutathione S-transferase A4 leads to increased protein carbonylation, oxidative stress, and mitochondrial dysfunction. Diabetes 2010; 59: 1132-1142. doi:10.2337/ db09-1105.

79. 31. Lin Y, Berg AH, Iyengar P, et al. The hyperglycemiainduced inflammatory response in adipocytes: the role of reactive oxygen species. J Biol Chem 2005; 280: 4617-4626. doi:10.1074/jbc.M411863200.

80. Cordeiro RM. Reactive oxygen species at phospholipid bilayers: Distribution, mobility and permeation. Biochim Biophys Acta - Biomembr 2014; 1838: 438-444. doi:10.1016/j. bbamem.2013.09.016.

81. Han CY. Roles of reactive oxygen species on insulin resistance in adipose tissue. Diabetes Metab J 2016; 40: 272-279. doi:10.4093/dmj.2016.40.4.272.

82. Nott TJ, Petsalaki E, Farber P, et al. Phase transition of a disordered nuage protein generates environmentally responsive membraneless organelles. Mol Cell 2015; 57: 936-947. doi:10.1016/j.molcel.2015.01.013.

83. Nott TJ, Craggs TD, Baldwin AJ. Membraneless organelles can melt nucleic acid duplexes and act as biomolecular filters. Nat Chem 2016; 8: 569-575. doi:10.1038/nchem.2519.

84. Feric M, Vaidya N, Harmon TS, et al. Coexisting liquid phases underlie nucleolar subcompartments. Cell 2016; 165: 1686-1697. doi:10.1016/j.cell.2016.04.047.

85. Wheeler JR, Matheny T, Jain S, Abrisch R, Parker R. Distinct stages in stress granule assembly and disassembly. Elife 2016; 5. doi:10.7554/eLife.18413. 